\title{
Overview of diagnosis and management of paediatric headache. Part II: therapeutic management
}

\author{
Cristiano Termine $\cdot$ Aynur Özge $\cdot$ Fabio Antonaci $\cdot$ \\ Sophia Natriashvili • Vincenzo Guidetti • \\ Çiçek Wöber-Bingöl
}

Received: 15 March 2010/Accepted: 7 September 2010/Published online: 18 December 2010

(C) Springer-Verlag 2010

\begin{abstract}
A thorough evaluation of headache in children and adolescents is necessary to make the correct diagnosis and initiate treatment. In part 1 of this article (Özge et al. in J Headache Pain, 2010), we reviewed the diagnosis of headache in children and adolescents. In the present part, we will discuss therapeutic management of primary headaches. An appropriate management requires an individually tailored strategy giving due consideration to both non-pharmacological and pharmacological measures. Non-pharmacological treatments include relaxation training, biofeedback training, cognitive-behavioural therapy, different psychotherapeutic approaches or combinations of these treatments. The data supporting the effectiveness of these therapies are less clearcut in children than in adults, but that is also true for the data
\end{abstract}

C. Termine

Child Neuropsychiatry Unit, Department of Experimental Medicine, University of Insubria, Como, Italy

A. Özge

Department of Neurology,

Mersin University School of Medicine,

Mersin, Turkey

F. Antonaci

Unit of Pavia, University Center for Adaptive Disorders

and Headache (UCADH), Pavia, Italy

S. Natriashvili · Ç. Wöber-Bingöl ( $\square)$

Department of Psychiatry of Childhood and Adolescence,

Medical University of Vienna, Währinger Gürtel 18-20,

1090 Vienna, Austria

e-mail: yasar.woeber-bingoel@meduniwien.ac.at

V. Guidetti

Department of Child and Adolescent Neuropsychiatry,

University La Sapienza, Rome, Italy supporting medical treatment. Management of migraine and TTH should include strategies relating to daily living activities, family relationships, school, friends and leisure time activities. In the pharmacological treatment age and gender of children, headache diagnosis, comorbidities and side effects of medication must be considered. The goal of symptomatic treatment should be a quick response with return to normal activity and without relapse. The drug should be taken as early as possible and in the appropriate dosage. Supplementary measures such as rest in a quiet, darkened room is recommended. Pharmaco-prophylaxis is only indicated if lifestyle modification and non-pharmacological prophylaxis alone are not effective. Although many prophylactic medications have been tried in paediatric migraine, there are only a few medications that have been studied in controlled trials. Multidisciplinary treatment is an effective strategy for children and adolescents with improvement of multiple outcome variants including frequency and severity of headache and school days missed because of headache. As a growing problem both children and families should be informed about medication overuse and the children's drug-taking should be checked.

Keywords Migraine - Tension-type headache · Symptomatic treatment . Pharmacological prophylaxis . Non-pharmacological treatment

\section{Introduction}

Headache is the most common complaint in children and adolescents. The incidence of childhood migraine and frequent headache has substantially increased over the past 30 years. The increased incidence is alarming and may be secondary to lifestyle changes but also due to increased 
awareness of the disease in this age group. Primary headache (especially migraine and tension type headache, TTH) is the most important cause of headaches in this age group. In part 1 of this article [1] we reviewed the diagnosis of headache in children and adolescents. In the present part, we will discuss therapeutic management.

\section{Management of headaches}

The general principles of management of headache in children and adolescents can be summarized as follows:

- Establish the diagnosis.

- Look for possible somatic and psychiatric comorbidities [2-6].

- Ask for triggers and assess degree of disability.

- Educate the child and family about the condition.

- Use a headache calendar to establish the characteristics of headache and associated symptoms.

- Establish realistic expectations and set appropriate goals.

- Discuss the expected benefits of pharmacological and non-pharmacological therapy and the time course to achieve them.

- Reduce the emotional mechanisms (on a personal level, within the family and at school) that provoke stress and may favour headache attacks.

- Advise to maintain a sound rhythm in daily life, which includes regular meals, sufficient fluid intake, physical exercise and sleep.

- Advise how to cope with trigger factors.

An algorithm for the diagnostic and therapeutic management of migraine is shown in Fig. 1.

Non-pharmacological treatments

\section{Non-pharmacological treatment of migraine}

Behavioural interventions, particularly biofeedback and relaxation therapy have demonstrated their effectiveness in the treatment of both adults and older children with migraine in controlled trials. The physiological basis for their effectiveness is unclear, but data from one trial suggest that levels of plasma beta-endorphin can be altered by relaxation and biofeedback therapies. The data supporting the effectiveness of behavioural therapies are less clear-cut in children than in adults, but that is also true for the data supporting medical treatment. This is due in part to methodological issues, especially the lack of specific tests for migraine, which has hampered research and helped leading to an inappropriate de-emphasis on care for childhood headache. In addition, migraine headaches in children are often briefer and have a higher rate of spontaneous remission than those experienced by adults, making it difficult to separate effective from ineffective treatments [7-9].

Starting from the consideration that children and adolescents with headache show greater indices of psychopathology [10-14] and show higher risk of developing psychological disorders in adulthood than healthy controls [15], different psychotherapeutic approaches are sometimes provided in clinical practice. Relaxation and cognitive-behavioural techniques have been found to reduce the intensity and frequency of headache in children and adolescents [16, 17].

Prospective, randomized, partly double-blind, placebocontrolled, parallel-group trial showed that Butterbur root extract and music therapy might be superior to placebo and may represent promising treatment approaches in the prophylaxis of paediatric migraine [18].

The specialists involved in the assessment and care of headache patients should strive to increase their knowledge of alternative therapies, so as to be better equipped to guide patients towards safe, economical and potentially effective treatments, rather than useless, costly or dangerous ones.

\section{Non-pharmacological treatment of TTH}

Behavioural headache treatments include relaxation training, biofeedback training, cognitive-behavioural therapy or combinations of these treatments. Among behavioural headache treatments, the two most common types of biofeedback for headache have been electromyographic biofeedback for TTH and "handwarming" or thermal biofeedback for migraine [9, 19-22]. Magnesium salt seems to be effective in treating the paediatric episodic and chronic TTH (ETTH, CTTH), but further well-controlled studies are needed [23].

There are restricted data about the natural history of childhood and adolescent TTH. It is accepted that over than $50 \%$ of the sufferers improve with a comprehensive headache managements. The most important predictors of prognosis are comorbid medical and psychological conditions and family problems [24, 25].

Pharmacological treatments

\section{Pharmacological treatment of migraine}

The data on efficacy and safety of medications in children are limited. Therefore, it may be necessary to use medications off label strictly weighing up the benefits and risks. However, medications which have shown efficacy in adults must not be used routinely in younger patients (please refer to Ref. [26]). Only few randomized placebo-controlled 
Fig. 1 Algorithm for the diagnostic and therapeutic management of migraine

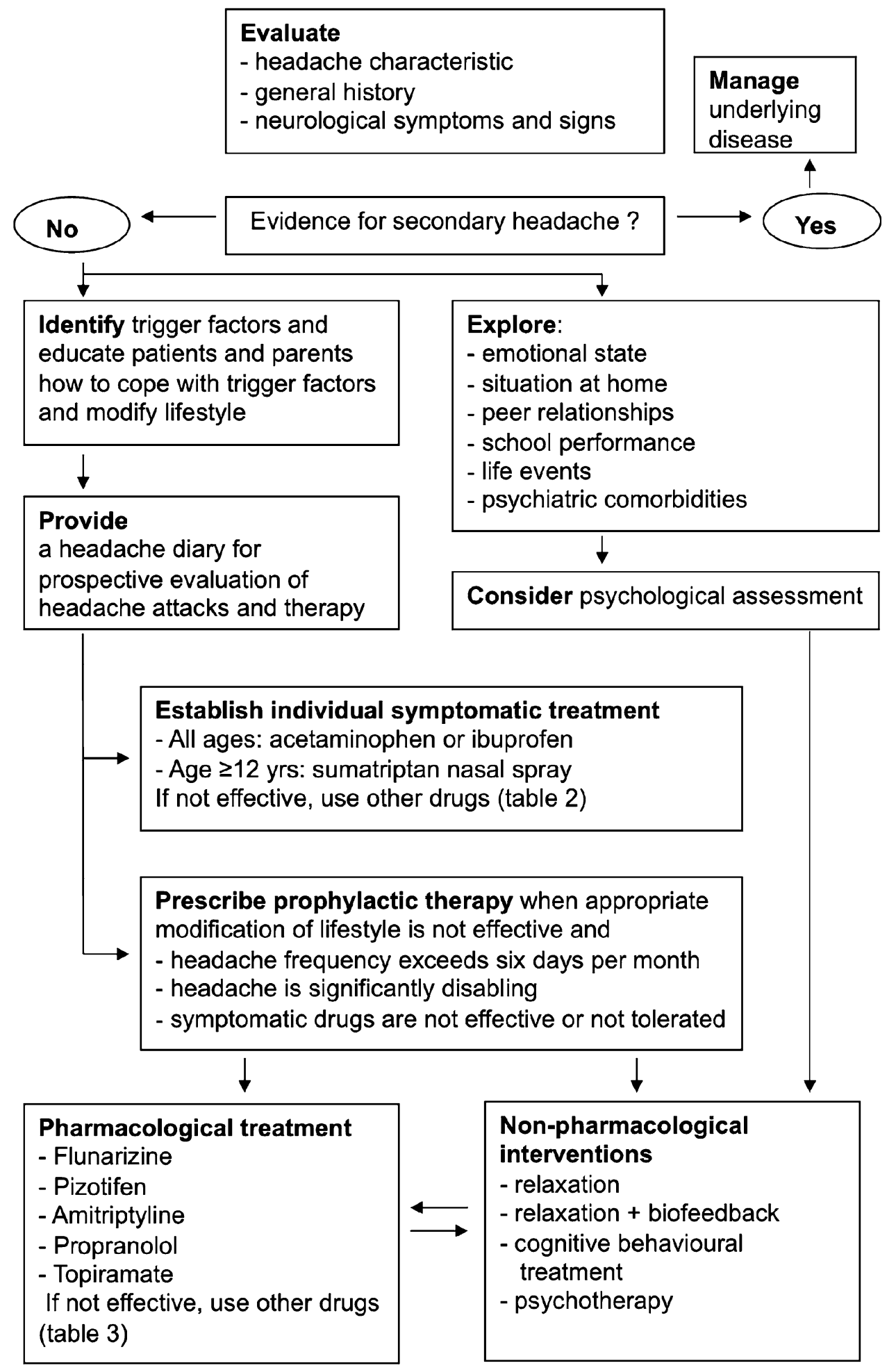

clinical trials have been conducted in paediatric headache patients for both acute and preventive drugs. Moreover, the few published studies show a high placebo response rate in children, up to $55 \%$ for prophylactic drugs, up to $69 \%$ for symptomatic ones. Such high placebo response rates drastically reduce the possibility to find effective agents (in terms of statistically significant superiority over placebo) and may lower the interest of pharmaceutical companies and independent researchers to perform new clinical trials in this field. On the other hand, the placebo effect is a psychobiological phenomenon that can be attributed to different mechanisms [27]; it should be properly used by 
the physician, simply bearing in mind that any medical treatment is surrounded by a psychosocial context that affects the therapeutic outcome.

The pharmacological treatment of migraine consists of symptomatic and/or prophylactic therapy. The former is aimed at relieving or ameliorating the symptoms of an acute attack, whereas prophylactic therapy, which requires the daily intake of medication for a certain period of time, decreases the frequency of the attacks and the severity of pain.

Symptomatic drug treatment The goal of treatment should be a quick response with return to normal activity and without relapse. Several key concepts should be made known to patients. Medication use should be limited to avoid medication overuse headache. It is important that an appropriate dose is used. Medications should be taken shortly after onset of migraine headache to optimize the effect, even though scientific evidence supporting this recommendation is lacking. The medication should be available to the patients also at school. Allodynia during a migraine in adults correlates with response to treatment of acute migraine with triptans and the progressive nature of migraine. This has emphasized the importance of early recognition of headache and appropriate treatment. Allodynia has recently been shown to be present in $37 \%$ of children during their migraine. Allodynia is often not routinely evaluated during a headache history even though there may be potential therapeutic implications. Prominent scalp symptoms include sensitivity to touch and difficulty brushing hair [28-30].

The available efficacy data about symptomatic drugs [31-46] are summarized in Tables 1 and 2. The following findings should be kept in mind:

- At $1 \mathrm{~h}$ acetaminophen tended to be slightly more effective (39\% of children relieved) than ibuprofen ( $37 \%$ of children relieved), but $2 \mathrm{~h}$ after administration ibuprofen was more effective (68 vs. $54 \%$ ).

- Sumatriptan nasal spray was superior to placebo and was well tolerated. No serious adverse events occurred with taste disturbance as the most common one.

- Pain relief at $2 \mathrm{~h}$ was achieved in significantly more attacks treated with rizatriptan 5-mg tablets (77\%) or with rizatriptan 5-mg wafer (77\%) than with standard care $(64 \%)$.

- Pain relief rates after $2 \mathrm{~h}$ were $28 \%$ for placebo, $62 \%$ for zolmitriptan and $69 \%$ for ibuprofen (placebo vs. zolmitriptan $p<0.05$; placebo vs. ibuprofen $p<0.05$ ). Both drugs are well tolerated with only mild side effects.

- The Food Drug Administration has recently approved almotriptan for the acute treatment of migraine headache in adolescents. Nevertheless, almotriptan is still not approved in Europe.

- There are limited data about other triptans.
- In summary, there is moderate evidence that analgesics (acetaminophen and ibuprofen) and nasal-spray sumatriptan are more effective than placebo treatment. Based on the available literature, no differences in effect were found between the different compounds.

There is a lack of studies addressing the question of treatment in the emergency department of children with migraine. Future studies should focus on finding the best first-line agent for mild to moderate attacks in the emergency department and to confirm the usefulness of prochlorperazine as treatment for severe attack or status migrainosus. In the latter studies, attention should be given to adverse drug reactions associated with prochlorperazine. Furthermore, treatment to decrease the recurrence of migraine attack and the need for rescue medications after discharge from the emergency department should also be carefully evaluated $[30,48]$.

Prophylactic drug treatment Pharmaco-prophylaxis is only indicated if lifestyle modification and non-pharmacological prophylaxis alone are not effective. Although many prophylactic medications have been tried in paediatric migraine, there are only a few medications that have been studied in controlled trials. Prophylactic medications are recommended only when migraines are occurring with sufficient frequency (usually 3-4 per month) and severity to impact a patient's daily function or quality of life (e.g. missing school). To minimize adverse effects, prophylactic medications are started at the lowest dose and titrated upward as needed. They have to give a through time period (at least 4-6 months), and both comorbidities and side effects of the drug have to be taken into consideration [30, 49].

Prophylactic drugs evaluated in placebo-controlled and open-label trials for migraine [50-71] have been summarized in Table 3. The following findings should be kept in mind:

- Flunarizine is an effective drug. Its use is limited by daytime sedation found in $10 \%$ of the patients and weight gain in more than $20 \%$. Because of probable D2 receptor interaction it should not be given for more than 3 months (administering it in the early evening can avert daytime sleepiness, dosage $5 \mathrm{mg} / \mathrm{die}$ ) [72, 73].

- Propranolol was found to be superior to placebo in one randomized controlled trial and not effective in two others. It was found to activate asthma in subjects with atopic disorders or a positive history of atopic disorders, and there are no follow-up studies concerning long-term risks of betablockers. Therefore, some centres do not use betablockers for migraine prophylaxis in children.

- The overall positive response rate of cyproheptadine was $83 \%$ and common side effects included sedation and increased appetite. 
Table 1 Symptomatic drugs for migraine management evaluated in placebo-controlled and open clinical trials

\begin{tabular}{|c|c|c|c|c|c|c|c|c|c|}
\hline \multirow[t]{2}{*}{ References } & \multirow[t]{2}{*}{ Drug } & \multirow{2}{*}{$\begin{array}{l}\text { Study } \\
\text { design }\end{array}$} & \multirow{2}{*}{$\begin{array}{l}\text { Evidence } \\
\text { level }\end{array}$} & \multirow[t]{2}{*}{ Dose } & \multirow{2}{*}{$\begin{array}{l}\text { Age } \\
\text { (years) }\end{array}$} & \multirow{2}{*}{$\begin{array}{l}\text { Number of } \\
\text { patients }\end{array}$} & \multicolumn{2}{|c|}{ Responders (\%) } & \multirow[t]{2}{*}{$p$ value } \\
\hline & & & & & & & $\begin{array}{l}\text { Active } \\
\text { drug }\end{array}$ & Placebo & \\
\hline Hamalainen et al. [31] & Ibuprofen & RCT & A & $10 \mathrm{mg} / \mathrm{kg}$ & $4-16$ & 88 & 68 & 37 & $<0.05$ \\
\hline Lewis et al. [32] & Ibuprofen & RCT & & $7.5 \mathrm{mg} / \mathrm{kg}$ & $6-12$ & 84 & 76 & 53 & 0.006 \\
\hline Evers et al. [33] & Ibuprofen & RCT & & $200-400 \mathrm{mg}$ & $6-18$ & 32 & 69 & 28 & $<0.05$ \\
\hline Hamalainen [31] & Acetaminophen & RCT & B & $15 \mathrm{mg} / \mathrm{kg}$ & $4-16$ & 88 & 54 & 37 & $<0.05$ \\
\hline Hamalainen et al. [34] & Dihydroergotamine & RCT & $\mathrm{C}$ & $20,40 \mu \mathrm{g} / \mathrm{kg}$ & $5-15$ & 12 & 58 & 16 & NS \\
\hline Ueberall [35] & Sumatriptan nasal & RCT & A & $20 \mathrm{mg}$ & $6-10$ & 14 & 86 & 43 & 0.03 \\
\hline Winner et al. [36] & Sumatriptan nasal & RCT & & $5-10-20 \mathrm{mg}$ & $12-17$ & 510 & $66^{\mathrm{a}}$ & 53 & $<0.05$ \\
\hline Ahonen et al. [37] & Sumatriptan nasal & RCT & & $10-20 \mathrm{mg}$ & $8-17$ & 83 & 64 & 39 & 0.003 \\
\hline Winner et al. [38] & Sumatriptan nasal & RCT & & $20 \mathrm{mg}$ & $12-17$ & 738 & 61 & 52 & NS \\
\hline Hamalainen et al. [39] & Sumatriptan oral & RCT & $\mathrm{C}$ & $50-100 \mathrm{mg}$ & $8-16$ & 23 & 30 & 22 & NS \\
\hline Mac Donald [40] & Sumatriptan sc. & OT & $\mathrm{C}$ & $3-6 \mathrm{mg}$ & $6-16$ & 17 & 64 & - & - \\
\hline Linder [41] & Sumatriptan sc. & OT & & $0.06 \mathrm{mg} / \mathrm{kg}$ & $6-18$ & 50 & 78 & - & - \\
\hline Winner et al. [42] & Rizatriptan & RCT & $\mathrm{C}$ & $5 \mathrm{mg}$ & $12-17$ & 196 & 66 & 56 & NS \\
\hline Visser et al. [43] & Rizatriptan & $\mathrm{RCT}$ & & $5 \mathrm{mg}$ & $12-17$ & 234 & 68 & 69 & NS \\
\hline Visser et al. [43] & Rizatriptan & OT & & $5 \mathrm{mg}$ & $12-17$ & 686 & 77 & - & - \\
\hline Linder and Dowson [44] & Zolmitriptan oral & OT & $\mathrm{C}$ & $2.5-5 \mathrm{mg}$ & $12-17$ & 38 & $88-70$ & - & - \\
\hline Evers et al. [33] & Zolmitriptan oral & RCT & & $2.5 \mathrm{mg}$ & $6-18$ & 32 & 62 & 28 & $<0.05$ \\
\hline Charles [45] & Almotriptan oral & OT & B & $6.25-12.5 \mathrm{mg}$ & $11-17$ & 15 & 86 & - & - \\
\hline Linder et al. [46] & Almotriptan oral & RCT & & $6.25-12.5-25 \mathrm{mg}$ & $12-17$ & 866 & $67-73$ & 55 & $<0.001$ \\
\hline
\end{tabular}

Evidence level: findings regarding symptomatic drugs were reviewed and the recommendations were categorized into different levels (A-C) [47]. Level A: two or more clinically controlled, randomized studies carried out according to good clinical practice (GCP), versus placebo or versus active treatment of proven efficacy. Level B: one clinically controlled, randomized study carried out according to GCP or more than one well-designed clinical case-control study or cohort study. Level C: favourable judgment of two-third of the Ad Hoc Committee members, historical controls, non-randomized studies, case reports

$N S$ no statistically significant difference between active drug and placebo, $R C T$ randomized controlled trial, $O T$ open trial

a $5 \mathrm{mg}$

Table 2 Summary of the efficacy of medication used to treat acute migraine attacks in children and adolescents [45]

\begin{tabular}{|c|c|c|c|c|}
\hline & \multicolumn{4}{|l|}{ Outcome } \\
\hline & Pain relief & Pain-free & Recurrence & Need for rescue medications \\
\hline \multicolumn{5}{|l|}{ Oral medication } \\
\hline Acetaminophen $(n=1)$ & + & - & - & - \\
\hline DHE $(n=1)$ & - & - & - & - \\
\hline Ibuprofen $(n=3)$ & + & \pm & - & \pm \\
\hline Rizatriptan $(n=3)$ & \pm & - & - & \pm \\
\hline Sumatriptan $(n=1)$ & - & \pm & - & - \\
\hline Zolmitriptan $(n=2)$ & \pm & \pm & - & + \\
\hline \multicolumn{5}{|l|}{ Intranasal medication } \\
\hline Sumatriptan $(n=4)$ & \pm & \pm & - & \pm \\
\hline \multicolumn{5}{|l|}{ Intravenous medications } \\
\hline Prochlorperazine $(n=1)$ & + & $?$ & - & $?$ \\
\hline Ketorolac $(n=1)^{*}$ & $?$ & $?$ & $?$ & $? \pm$ \\
\hline
\end{tabular}

+ studies showing consistent positive results or a study showing positive result; - studies showing consistent negative results or a study showing negative result; \pm studies showing inconsistent results; ? not evaluated

* Used as a comparative agent against prochlorperazine 
Table 3 Prophylactic drugs for migraine management evaluated in placebo-controlled and open clinical trials

\begin{tabular}{|c|c|c|c|c|c|c|c|}
\hline References & Drug & Daily dose & $\begin{array}{l}\text { Age in } \\
\text { (years) }\end{array}$ & $\begin{array}{l}\text { Number of } \\
\text { patients }\end{array}$ & $\begin{array}{l}\text { Study } \\
\text { design }\end{array}$ & $\begin{array}{l}\text { Evidence } \\
\text { level }\end{array}$ & $\begin{array}{l}\% \text { responders } \\
\text { or } p \text { values }(*)\end{array}$ \\
\hline \multicolumn{8}{|l|}{ Antihypertensive drugs } \\
\hline Ludvigsson [50] & Propranolol & $60-120 \mathrm{mg}$ & $7-16$ & 28 & RCT & $\mathrm{C}$ & 82 vs. $14 \%$ \\
\hline Forsythe et al. [51] & Propranolol & $80 \mathrm{mg}$ & $9-15$ & 39 & $\mathrm{RCT}$ & & NS \\
\hline Olness et al. [52] & Propranolol & $3 \mathrm{mg} / \mathrm{kg}$ & $6-12$ & 28 & $\mathrm{RCT}$ & & NS \\
\hline Sillampää [53] & Clonidine & $25-50 \mu \mathrm{g}$ & $\leq 15$ & 57 & $\mathrm{RCT}$ & $\mathrm{C}$ & NS \\
\hline Sills et al. [54] & Clonidine & $0.07-0.1 \mathrm{mg}$ & $7-14$ & 43 & $\mathrm{RCT}$ & & NS \\
\hline \multicolumn{8}{|l|}{ Calcium channel blockers } \\
\hline Guidetti et al. [55] & Flunarizine & $5 \mathrm{mg}$ & $10-13$ & 12 & OT & A & $66 \%$ \\
\hline Sorge et al. [56] & Flunarizine & $5 \mathrm{mg}$ & $5-11$ & 63 & RCT & & $\begin{array}{l}p<0.001 \text { (HA frequency) } \\
p<0.01 \text { (HA duration) }\end{array}$ \\
\hline Visudtibhan et al. [57] & Flunarizine & $5-10 \mathrm{mg}$ & $7-15$ & 21 & OT & & $\% 66$ \\
\hline Battistella et al. [58] & Nimodipine & $10-20 \mathrm{mg}$ & $7-18$ & 37 & RCT & $\mathrm{C}$ & NS \\
\hline \multicolumn{8}{|l|}{ Serotonergic drugs } \\
\hline Gillies et al. [59] & Pizotifen & $1-1.5 \mathrm{mg}$ & $7-14$ & 47 & $\mathrm{RCT}$ & $\mathrm{C}$ & NS \\
\hline Lewis et al. [60] & Cyproheptadine & $2-8 \mathrm{mg}$ & $3-12$ & 30 & OT & $\mathrm{C}$ & $83 \%$ \\
\hline \multicolumn{8}{|l|}{ Antidepressants } \\
\hline Battistella et al. [61] & Trazodone & $1 \mathrm{mg} / \mathrm{kg}$ & $7-18$ & 35 & $\mathrm{RCT}$ & $\mathrm{C}$ & NS \\
\hline Hershey et al. [62] & Amitriptyline & $1 \mathrm{mg} / \mathrm{kg}$ & $9-15$ & 192 & OT & $\mathrm{C}$ & $80 \%$ \\
\hline Lewis et al. [60] & Amitriptyline & $10 \mathrm{mg}$ & $3-12$ & 73 & OT & & $89 \%$ \\
\hline \multicolumn{8}{|l|}{ Anticonvulsants } \\
\hline Caruso et al. [63] & Divalproex sodium & $15-45 \mathrm{mg} / \mathrm{kg}$ & $7-16$ & 42 & OT & B & $76 \%$ \\
\hline Sedaroglu et al. [64] & Divalproex sodium & $500-1,000 \mathrm{mg}$ & $9-17$ & 10 & OT & & $\begin{array}{l}p=0.000 \text { (HA severity) } \\
p=0.002 \text { (HA frequency) } \\
p=0.001 \text { (HAduration) }\end{array}$ \\
\hline Hershey et al. [65] & Topiramate & $1.4 \pm 0.7 \mathrm{mg} / \mathrm{kg}$ & $8-15$ & 75 & OT & A & $p<0.001$ (HA frequency) \\
\hline Winner et al. [66] & Topiramate & $2-3 \mathrm{mg} / \mathrm{kg}$ & $6-15$ & 162 & RCT & & NS \\
\hline Lewis et al. [67] & Topiramate & $100 \mathrm{mg}$ & $12-17$ & 103 & $\mathrm{RCT}$ & & $72 \%$ \\
\hline Miller [68] & Levetiracetam & $250-1,500 \mathrm{mg}$ & $3-17$ & 19 & OT & B & $p<0.0001$ (HA frequency) \\
\hline Pekalnis et al. [69] & Levetiracetam & $250-1,500 \mathrm{mg}$ & $6-17$ & 20 & OT & & $p<0.0001$ (HA frequency) \\
\hline Belman et al. [70] & Gabapentin & $15 \mathrm{mg} / \mathrm{kg}$ & $6-17$ & 18 & OT & $\mathrm{C}$ & $80 \%$ \\
\hline Pakalnis and Kring [71] & Zonisamide & $5.8 \mathrm{mg} / \mathrm{kg}$ & $10-17$ & 12 & OT & $\mathrm{C}$ & $66 \%$ \\
\hline
\end{tabular}

Evidence level: findings regarding symptomatic drugs were reviewed and the recommendations were categorized into different levels (A-C) [47]. Level A: two or more clinically controlled, randomized studies carried out according to good clinical practice (GCP), versus placebo or versus active treatment of proven efficacy. Level B: one clinically controlled, randomized study carried out according to GCP or more than one well-designed clinical case-control study or cohort study. Level C: favourable judgment of two-thirds of the Ad Hoc Committee members, historical controls, non-randomized studies, case reports

$N S$ no statistically significant difference between active drug and placebo, $H A$ headache, $R C T$ randomized controlled trial, $O T$ open trial

* The $\%$ is expressed as overall $\%$ of responders (OT) or active-drug vs placebo \% of responders (RCT); $p$ values refer to active drug versus placebo comparisons (RCT) or pre-treatment versus post-treatment comparison of headache characteristics (OT)

- There are limited confirmative data about trazodone.

- Amitriptyline $(1 \mathrm{mg} / \mathrm{kg})$ is an effective drug with an $84.2-89 \%$ positive response rate and only mild sedation was reported as side effect.

- Divalproex sodium $(15-45 \mathrm{mg} / \mathrm{kg} /$ day $)$ is an effective drug with $50 \%$ headache reduction seen in $78.5 \%$ of patients, $75 \%$ reduction in $14.2 \%$ of patients, and $9.5 \%$ of patients became headache-free after 4 months of treatment. The observed side effects were dizziness, drowsiness and increase in appetite.

- Topiramate is an effective drug for the reduction of headache frequency, severity and duration. The most common side effects reported were cognitive (12.5\%), weight loss (5.6\%) and sensory (2.8\%).

- There are limited data about levetiracetam, gabapentin and zonisamide. 


\section{Pharmacological treatment of TTH}

Most TTH is best managed by primary care. ETTH is selflimiting, but children and their parents generally consult doctors when headaches occur frequently and are no longer responsive to analgesics. Medication overuse can be a common problem in patients with frequent headache. The treatment of migraine and TTH overlaps. Both require acute treatment, either behavioural or pharmaceutical. Behavioural treatment is needed for all types of TTH. Preventive pharmaceutical treatment is needed for frequent TTH if lifestyle modification and non-pharmacological treatment alone are not effective. Although childhood TTH is often treated with medication, few studies have been published the efficacy of medication in paediatric TTH. More studies in children need to be done regarding the treatment of this common disorder. The lack of availability and cost of non-pharmacological interventions might diminish the use of some treatment modalities [74, 75].

For acute treatment of ETTH, paracetamol, aspirin and combination analgesics are effective and inexpensive drugs. Non-steroidal anti-inflammatory drugs are also effective first-line therapeutics for ETTH in adults. In children younger than 15 years, aspirin is not recommended because of the concern regarding Reye's syndrome. Paracetamol seems to be safe even in young children [75-78].

Frequent headaches in children and adolescents often require preventive management. Prophylactic pharmacological treatment should be considered in CTTH if nonpharmacological management is inadequate. For children with frequent headache, amitriptyline might be beneficial, although no placebo-controlled studies have been performed [62].

\section{Treatment of cluster headache}

Several treatment alternatives have been tried in cases reported in the literature. According to these data, the most effective symptomatic treatments are oxygen [79-82], sumatriptan [81, 83] and acetylsalicylic acid [80-84]. Prophylactic treatments reported in literature are prednisone/prednisolone [85, 86], indomethacin [84], pizotifen [81], verapamil [81, 82, 87], methysergide [79, 83, 85], loratadine [88], astemizole [88] and flunarizine [89]. No controlled study has been reported.

If oxygen is administered at the onset of an attack via a non-rebreathing facial mask at a flow rate of at least $7 \mathrm{l} / \mathrm{min}$, approximately $70 \%$ of patients will obtain pain relief within $15 \mathrm{~min}$. This therapy has obvious practical limitations and requires oxygen being readily available at the patient's home $[85,90]$. Considering the unbearable pain intensity, off-label use of sumatriptan nasal spray or subcutaneous sumatriptan may be necessary. Ergotamine has also been used. It is not recommended for acute $\mathrm{CH}$-treatment in children, but might be given in the evening for preventing night-time attacks. Children between 6 and 9 years of age should receive $0.1 \mathrm{mg} / \mathrm{dose}$, those between 9 and 12 years of age should receive $0.5 \mathrm{mg}$, and those between 12 and 16 years of age should receive $0.75 \mathrm{mg} /$ dose. Lidocaine applied with a spray bottle or by dropping in the nostril ipsilateral to pain achieves moderate pain relief, and it may be useful as an adjunctive therapy. Although the reason for steroid efficacy is unknown, the use of cortisone in the acute period can stop the attacks and may help to prevent further attacks. In adolescents a marked relief of cluster headache in $77 \%$ of 77 episodic cluster headache patients, and a partial relief in another $12 \%$ of patients treated with prednisone was reported $[85,90]$. For prophylactic treatment the efficacy of verapamil has been attributed to a possible stabilization of vascular tone. It is generally well tolerated and can be used in combination with corticosteroids, sumatriptan and ergotamine [91, 92].

\section{Life quality of headaches}

Health-related quality of life (QOL) is an emerging area of headache research with a direct impact on patient adherence, patient satisfaction and treatment effectiveness. On the other hand, the assessment of QOL in children is difficult, since measures must consider children's changing cognitive and social development [93, 94]. Data-based analyses revealed that children with frequent or severe headaches (FSH) were significantly more likely than those without FSH to exhibit high levels of emotional, conduct, inattention-hyperactivity, and peer problems and were significantly more likely than children without FSH to be upset or distressed by their difficulties and to have their difficulties interfere with home life, friendships, classroom learning and leisure activities [95]. Subjects familiar with headache experienced more stress, fatigue, depression, and somatic symptoms; they felt less strong, had a less cheerful mood and reported lower satisfaction with health and with life in general than the subjects who never had headaches [96]. The impact of headaches on QOL is similar to that found for other chronic illness conditions, with impairments in school and emotional functioning being the most prominent [97]. Headache is the third most common cause among illness-related causes of school absenteeism resulting in substantial impairment among paediatric patients [98]. A specific questionnaire (PedMIDAS) provides a tool to assess the impact of migraines in children and to monitor response to treatment. Further research should focus on additional validation of the PedMIDAS 
using a larger population and sampling from other populations (e.g. primary care and community samples) [99].

\section{Conclusions}

- Management of migraine and TTH should include strategies relating to daily living activities, family relationships, school, friends and leisure time activities.

- Management should be completed by education (both of the children and parents), non-pharmacological interventions and psychosocial support.

- With reference to symptomatic treatment, the drug should be taken as early as possible and in the appropriate dosage. In cases with early onset of nausea and/or vomiting endorectal or parenteral administration should be preferred. Antiemetic drugs should not be provided if the child vomits only once or headache stops after vomiting. If an antiemetic is required, ondansetron may be preferred for its good tolerability. Supplementary measures such as rest in a quiet, darkened room is recommended.

- Multidisciplinary treatment is an effective strategy for children and adolescents with improvement of multiple outcome variants including frequency and severity of headache and school days missed because of headache.

- In the pharmacological treatment age and gender of children, headache diagnosis, comorbidities, need and side effects of medication must be considered.

- As a growing problem both children and families should be informed about medication overuse and the children's drug-taking should be checked.

- Regular follow-up care is needed, especially for those children with more severe initial headache presentation.

Conflict of interest None.

\section{References}

1. Özge A, Termine C, Antonaci F, Natriashvili S, Guidetti V, Wöber-Bingöl Ç (2010) Overview of the diagnosis and management of paediatric headache. Part I-diagnosis. J Headache Pain

2. Guidetti V, Galli F (2002) Psychiatric comorbidity in chronic daily headache: pathophysiology, etiology, and diagnosis. Curr Pain Headache Rep 6(6):492-497

3. Hämäläinen ML (1998) Migraine in children. Guidelines for treatment. CNS Drugs 10:105-117

4. Bruni O, Galli F, Guidetti V (1999) Sleep hygiene and migraine in children and adolescents. Cephalalgia 19(Suppl. 25):S57-S59

5. Wöber C, Wöber-Bingöl Ç (2000) Clinical management of young patients presenting with headache. Funct Neurol 15(Suppl. 3): S89-S105
6. Carotenuto M, Guidetti V, Ruju F, Galli F, Tagliente FR, Pascotto A (2005) Headache disorders as risk factors for sleep disturbances in school aged children. J Headache Pain 6(4):268-270

7. Damen L, Bruijn J, Koes BW, Berger MY, Passchier J, Verhagen AP (2005) Prophylactic treatment of migraine in children. Part 1: a systematic review of non-pharmacological trials. Cephalalgia 6:373-383

8. Baumann RJ (2002) Behavioral treatment of migraine in children and adolescents. Paediatr Drugs 4(9):555-561

9. Andrasik F, Grazzi L, Usai S, D’Amico D, Leone M, Bussone G (2003) Brief neurologist-administered behavioral treatment of pediatric episodic tension-type headache. Neurology 60:12151216

10. Maratos J, Wilkinson M (1982) Migraine in children: a medical and psychiatric study. Cephalalgia 2(4):179-187

11. Lanzi G, Balottin U, Gamba N, Fazzi E (1983) Psychological aspects of migraine in children. Cephalalgia 3:18-20

12. Kowal A, Pritchard D (1990) Psychological characteristics of children who suffer from headache: a research note. J Child Psychol Psychiatr 31(4):637-649

13. Larsson B (1988) The role of psychological, health-behaviour and medical factors in adolescent headache. Dev Med Child Neurol 30(5):616-625

14. Guidetti V, Galli F, Fabrizi P, Giannantoni AS, Napoli L, Bruni O et al (1998) Headache and psychiatric comorbidity: clinical aspects and outcome in an 8-year follow-up study. Cephalalgia 18:455-462

15. Fearon P, Hotopf M (2001) Relation between headache in childhood and physical and psychiatric symptoms in adulthood: national birth cohort study. BMJ 322(7295):1145

16. Kazdin AE (2002) The state of child and adolescent psychotherapy research. Child Adolesc Mental Health 2:53-59

17. Eccleston C, Yorke L, Morley S, Williams AC, Mastroyannopoulou K (2003) Psychological therapies for the management of chronic and recurrent pain in children and adolescents. Cochrane Database Syst Rev (1):CD003968

18. Oelkers-Ax R, Leins A, Parzer P, Hillecke T, Bolay HV, Fischer $\mathrm{J}$ et al (2008) Butterbur root extract and music therapy in the prevention of childhood migraine: an explorative study. Eur $\mathrm{J}$ Pain 12(3):301-313

19. Eccleston C, Morley S, Williams A, Yorke L, Mastroyannopoulou K (2002) Systematic review of randomized controlled trials of psychological therapy for chronic pain in children and adolescents, with a subset meta-analysis of pain relief. Pain 99:157-165

20. Larsson B, Carlsson J, Fichtel A, Melin L (2005) Relaxation treatment of adolescent headache sufferers: results from a schoolbased replication series. Headache 45:692-04

21. Rains JC, Penzien DB, McCrory DC, Gray RN (2005) Behavioral headache treatment: history, review of the empirical literature, and methodological critique. Headache 45:92-109

22. Sarafino EP, Goehring P (2000) Age comparisons in acquiring biofeedback control and success in reduction headache pain. Ann Behav Med 22:10-16

23. Grazzi L, Andrasik F, Usai S, Bussone G (2005) Magnesium as a treatment for paediatric tension-type headache: a clinical replication series. Neurol Sci 25:338-341

24. Anttila P (2004) Tension-type headache in children and adolescents. Curr Pain Headache Rep 8(6):500-504

25. Abu-Arafeh I (2001) Chronic tension-type headache in children and adolescents. Cephalalgia 21:830-836

26. Silberstein SD (2000) Practice parameter: evidence-based guidelines for migraine headache (an evidence-based review). Neurology 55:754-762

27. Benedetti F, Mayberg HS, Wager TD, Stohler CS, Zubieta JK (2005) Neurobiological mechanisms of the placebo effect. J Neurosci 25:10390-10402 
28. Burstein R, Collin B (2000) An association between migraine and cutaneous allodynia. Ann Neurol 47:614-624

29. Eidlitz-Markus T, Shuper A, Gorali O, Zeharia A (2007) Migraine and cephalic cutaneous allodynia in pediatric patients. Headache 47:1219-1223

30. Hung RM, MacGregor DL (2008) Management of pediatric migraine: current concepts and controversies. Indian J Pediatr 75(11):1139-1148

31. Hämäläinen ML, Hoppu K, Valkeila E, Santavuori P (1997) Ibuprofen or acetaminophen for the acute treatment of migraine in children: a double-blind, randomized, placebo-controlled, crossover study. Neurology 48:102-107

32. Lewis DW, Kellstein D, Dahl G, Burke B, Frank LM, Toor S et al (2002) Children's ibuprofen suspension for the acute treatment of pediatric migraine headache. Headache 42:780-786

33. Evers S, Rahmann A, Kraemer C, Kurlemann G, Debus O, Husstedt IW et al (2006) Treatment of childhood migraine attacks with oral zolmitriptan and ibuprofen. Neurology 67:497-499

34. Hamalainen Ml, Hoppu K, Santavuori Pr (1997) Oral dihydroergotamine for therapy-resistant migraine attacks in children. Pediatr Neurol 16:114-117

35. Uebarall MA (1999) Intranasal sumatriptan for the acute treatment of migraine in children. Neurology 52:1507-1510

36. Winner P, Rothner AD, Saper J, Nett R, Asgharnejad M, Laurenza A et al (2000) A randomized, double-blind, placebo-controlled study of sumatriptan nasal spray in the treatment of acute migraine in adolescents. Pediatrics 106:989-997

37. Ahonen K, Hämäläinen ML, Rantala H, Hoppu K (2004) Nasal sumatriptan is effective in the treatment of migraine attacks in children. Neurology 62:883-887

38. Winner P, Rothner AD, Wooten JD, Webster C, Ames M (2006) Sumatriptan nasal spray in adolescent migraineurs: a randomized, double-blind, placebo-controlled, acute study. Headache 46:212-222

39. Hamalainen M, Hoppu K, Santavuori P (1997) Sumatriptan for migraine attacks in children: a randomized placebo-controlled study. Do children with migraine respond to oral sumatriptan differently than adults? Neurology 48:1100-1103

40. Mac Donald JT (1994) Treatment of juvenile migraine with subcutaneous sumatriptan. Headache 34:581-582

41. Linder SL (1996) Subcutaneous sumatriptan in the clinical setting: the first 50 consecutive patients with acute migraine in the pediatric neurology office practice. Headache 36:419-422

42. Winner P, Lewis D, Visser WH, Jiang K, Ahrens S, Evans JK (2002) Rizatriptan adolescent study group. Rizatriptan $5 \mathrm{mg}$ for the acute treatment of migraine in adolescents: a randomized, double-blind placebo-controlled study. Headache 42:49-55

43. Visser WH, Winner P, Strohmaier K, Klipfel M, Peng Y et al (2004) Rizatriptan protocol 059 and 061 study groups. Rizatriptan protocol 059 and 061 study groups. Rizatriptan $5 \mathrm{mg}$ for the acute treatment of migraine in adolescents: results from a doubleblind, single-attack study and two open-label, multiple-attack studies. Headache 44:891-899

44. Linder SL, Dowson AJ (2000) Zolmitriptan provides effective migraine relief in adolescents. Int J Clin Pract 54:466-469

45. Charles JA (2006) Almotriptan in the acute treatment of migraine in patients 11-17 years old: an open-label pilot study of efficacy and safety. J Headache Pain 7:95-97

46. Linder SL, Mathew NT, Cady RK et al (2008) Efficacy and tolerability of almotriptan in adolescents: a randomized, doubleblind, placebo controlled trial. Headache 48(9):1326-1336

47. "Ad Hoc Committee" (2001) Diagnostic, therapeutic guidelines for migraine, cluster headache. J Headache Pain 2(3):105-192

48. Bailey B, McManus BC (2008) Treatment of children with migraine in the emergency department: a qualitative systematic review. Pediatr Emerg Care 24(5):321-330
49. Lanzi G, Balottin U, Zambrino CA, Cernibori A, Del Bene E, Gallai V et al (1996) Guidelines and recommendations for the treatment of migraine in paediatric and adolescent patients. Funct Neurol 11:269-275

50. Ludvigsson J (1974) Propranolol used in prophylaxis of migraine in children. Acta Neurol 50:109-115

51. Forsythe WI, Gillies D, Sills MA (1984) Propranolol (Inderal) in the treatment of childhood migraine. Dev Med Child Neurol 26:737-741

52. Olness K, Macdonald JT, Uden DL (1987) Comparison of selfhypnosis and propranolol in the treatment of juvenile classic migraine. Pediatrics 79:593-597

53. Sillanpaa M (1977) Clonidine prophylaxis of childhood migraine and other vascular headache. A double blind study of 57 children. Headache 17:28-31

54. Sills M, Congdon P, Forsythe I (1982) Clonidine and childhood migraine. Dev Med Child Neurol 24:837-841

55. Guidetti V, Moscato D, Ottaviano S, Fiorentino D, Fornara R (1987) Flunarizine and migraine in childhood: an evaluation of endocrine function. Cephalalgia 7:263-266

56. Sorge F, De Simone R, Marano E, Nolano M, Orefice G, Carrieri $P$ (1988) Flunarizine in prophylaxis of childhood migraine. A double-blind, placebo-controlled crossover study. Cephalalgia $8: 1-6$

57. Visudtibhan A, Lusawat A, Chiemchanya S, Visudhiphan $\mathrm{P}$ (2004) Flunarizine for prophylactic treatment of childhood migraine. J Med Assoc Thai 87(12):1466-1470

58. Battistella PA, Ruffilli R, Moro R, Fabiani M, Bertoli S, Antolini A et al (1990) A placebo-controlled crossover trial of nimodipine in pediatric migraine. Headache 30:264-268

59. Gillies D, Sills M, Forsythe I (1986) Pizotifen (Sandomigran) in childhood migraine. A double-blind placebo controlled trial. Eur Neurol 25:32-35

60. Lewis DW, Diamond S, Scott D, Jones V (2004) Prophylactic treatment of pediatric migraine. Headache 44:230-237

61. Battistella PA, Ruffilli R, Cernetti R, Pettenazzo A, Baldin L, Bertoli S et al (1993) A placebo-controlled crossover trial using trazodone in pediatric migraine. Headache 33(1):36-39

62. Hershey AD, Powers SW, Bentti AL, Degrauw TJ (2000) Effectiveness of amitriptyline in the prophylactic management of childhood headaches. Headache 40:539-549

63. Caruso JM, Brown WD, Exil G, Gascon GG (2000) The efficacy of divalproex sodium in the prophylactic treatment of children with migraine. Headache 40:672-676

64. Serdaroglu G, Erhan E, Tekgul H, Oksel F, Erermis S, Uyar M et al (2002) Sodium valproate prophylaxis in childhood migraine. Headache 42:819-822

65. Hershey AD, Powers SW, Vockell AL, LeCates S, Kabbouche M (2002) Effectiveness of topiramate in the prevention of childhood headache. Headache 42:810-818

66. Winner P, Pearlman EM, Linder SL, Jordan DM, Fisher AC, Hulihan J (2005) Topiramate pediatric migraine study investigators. Topiramate for migraine prevention in children: a randomized, double-blind, placebo-controlled trial. Headache 45(10):1304-1312

67. Lewis D, Winner P, Saper J, Ness S, Polverejan E, Wang S, Kurland CL, Nye J, Yuen E, Eerdekens M, Ford L (2009) Randomized, double-blind, placebo-controlled study to evaluate the efficacy and safety of topiramate for migraine prevention in pediatric subjects 12 to 17 years of age. Pediatrics 123(3): 924-934

68. Miller GS (2004) Efficacy and safety of levetiracetam in pediatric migraine. Headache 44:238-243

69. Pakalnis A, Kring D, Meier L (2007) Levetiracetam prophylaxis in pediatric migraine-an open-label study. Headache 47(3): $427-430$ 
70. Belman Al, Milazo M, Savatic M (2001) Gabapentin for migraine prophylaxis in children. Ann Neurol 50(Suppl.1):S109

71. Pakalnis A, Kring D (2006) Zonisamide prophylaxis in refractory pediatric headache. Headache 46(5):804-807

72. Wöber C, Brücke T, Wöber-Bingöl C, Asenbaum S, Wessely P, Podreka I (1994) Dopamine D2 receptor blockade and antimigraine action of flunarizine. Cephalalgia 14(3):235-240

73. Wöber C, Wöber-Bingöl C, Koch G, Wessely P (1991) Longterm results of migraine prophylaxis with flunarizine and betablockers. Cephalalgia 11(6):251-256

74. Anttila P, Metsähonkala L, Aromaa M, Sourander A, Salminen J, Helenius $\mathrm{H}$ et al (2002) Determinants of tension-type headache in children. Cephalalgia 22:401-408

75. Anttila P (2006) Tension-type headache in childhood and adolescence. Lancet Neurol 5(3):268-274

76. Steiner TJ, Lange R, Voelker M (2003) Aspirin in episodic tension-type headache: placebo-controlled dose-ranging comparison with paracetamol. Cephalalgia 23:59-66

77. Dooley J (2009) The evaluation and management of paediatric headaches. Paediatr Child Health 14(1):24-30

78. Pini LA, Del Bene E, Zanchin G, Sarchielli P, Di Trapani G, Prudenzano MP et al (2008) Tolerability and efficacy of a combination of paracetamol and caffeine in the treatment of tensiontype headache: a randomised, double-blind, double-dummy, cross-over study versus placebo and naproxen sodium. J Headache Pain 9(6):367-373

79. Del Bene E, Poggioni M (1987) Typical and atypical cluster headache in childhood. Cephalalgia 7(Suppl.6):S128-S130

80. Evers S, Frese A, Majewski A, Albrecht O, Husstedt IW (2002) Age of onset in cluster headache: the clinical spectrum (three case reports). Cephalalgia 22:160-162

81. McNabb S, Whitehouse W (1999) Cluster headache-like disorder in childhood. Arch Dis Child 81:511-512

82. Spierings EL, Vincent AJ (1992) Familial cluster headache: occurrence in three generations. Neurology 42:1399-1400

83. Bordini CA, Arruda MA, Ciciarelli M, Daripa M, Martins Coelho J, Speciali JG (1997) Cluster headache: report of seven cases in three families. Funct Neurol 12:277-282

84. D'Cruz OF (1994) Cluster headaches in childhood. Clin Pediatr 33:241-242

85. Curless RG (1982) Cluster headaches in childhood. J Pediatr 101:393-395

86. Lampl C (2002) Childhood-onset cluster headache. Pediatr Neurol 27:138-140
87. Gallai B, Mazzotta G, Floridi F, Mattioni A, Baldi A, Alberti A et al (2003) Cluster headache in childhood and adolescence: oneyear prevalence in an out-patient population. J Headache Pain 4:132-137

88. Neubauer D, Kuhar M, Ravnik IM (1997) Antihistamine responsive cluster headache in a teenage girl. Headache 37:296-298

89. Garrido C, Tuna A, Ramos S, Temudo T (2001) Cluster headache in a 3 year old child. Rev Neurol 33:732-735

90. Kudrow L (1981) Response of cluster headache attacks to oxygen inhalation. Headache 21:1-4

91. Dodick D, Campbell JK (2000) Cluster headache. Diagnosis management and treatment. In: Silberstein SD, Lipton RB, Dalessio DJ (eds) Wolff's headache and other head pain, 7th edn. Oxford University Press, New York, pp 283-309

92. Majumdar A, Ahmed MA, Benton S (2008) Cluster headache in children-Experience from a specialist headache clinic. Eur $\mathrm{J}$ Paediatr Neurol 22

93. Akyol A, Kiylioglu N, Aydin I, Erturk A, Kaya E, Telli E et al (2007) Epidemiology and clinical characteristics of migraine among school children in the Menderes region. Cephalalgia 27(7):781-787

94. Powers SW, Patton SR, Hommel KA, Hershey AD (2004) Quality of life in paediatric migraine: characterization of agerelated effects using PedsQL 4.0. Cephalalgia 24:120-127

95. Strine TW, Okoro CA, McGuire LC, Balluz LS (2006) The associations among childhood headaches, emotional and behavioral difficulties, and health care use. Pediatrics 117(5): $1728-1735$

96. Karwautz A, Wöber C, Lang T, Böck A, Wagner-Ennsgraber C, Vesely C et al (1999) Psychosocial factors in children and adolescents with migraine and tension-type headache: a controlled study and review of the literature. Cephalalgia 19:32-43

97. Powers SW, Patton SR, Hommel KA, Hershey AD (2003) Quality of life in childhood migraines: clinical impact and comparison to other chronic illnesses. Pediatrics 112(1 Pt 1):e1-e5

98. Newacheck PW, Taylor WR (1992) Childhood chronic illness: prevalence, severity, and impact. Am J Public Health 82:364-371

99. Hershey AD, Powers SW, Vockell AL, LeCates S, Kabbouche MA, Maynard MK (2001) PedMIDAS: development of a questionnaire to assess disability of migraines in children. Neurology 57(11):2034-2039 